\title{
BASAL METABOLIC INDEX AND RETINOPATHY IN TYPE 2 DIABETICS.
}

\footnotetext{
1. MBBS, Mphil Physiology Senior Demonstrator Department of Physiology Fatima Memorial Medical and Dental College, Lahore.

2. MBBS, FCPS, FICO, FACS Fellowship Refractive and Corneal Surgery,

Associate Professor and Head Department of Ophthalmology Shahida Islam Medical and Dental College, Lodhran, Punjab.

3. MBBS

Senior Demonstrator Department of Physiology Fatima Memorial Medical and Dental College, Lahore.

4. MBBS, WMO

Shahida Islam Medical and Dental College, Lodhran, Punjab.

5. MBBS, M.Phil Physiology. Assistant Professo Department of Physiology Fatima Memorial Medical and Dental College, Lahore.
}

Correspondence Address: Dr. Kanwal ljaz MBBS, M.Phil Physiology

Senior Demonstrator Physiology

Fatima Memorial Medical and

Dental College, Lahore.

drkanwal81@yahoo.com

Article received on:

01/04/2019

Accepted for publication:

25/06/2019

Received after proof reading:

$25 / 06 / 2019$
Kanwal ljaz', Muhammad Luqman Ali Bahoo ${ }^{2}$, Mahwish Saeed ${ }^{3}$, Beenish Karamt ${ }^{4}$, Sobia Niaz ${ }^{5}$

ABSTRACT... Diabetes mellitus is major health concern owing to its morbidity and mortality attributed to the complications related to chronic hyperglycemia of T2DM. A darker aspect among these complication is threat to vision produced by diabetic retinopathy (DR). Obesity is among major risk factors for diabetes mellitus. Consequently, overweight and obese people are more vulnerable to develop DR. To compare the basal metabolic index in type two diabetics with and without diabetic retinopathy. Objective: To correlate basal metabolic index with diabetic retinopathy. Study Design: Comparative Cross sectional analysis. Setting: Type two diabetic patients were recruited from Outpatient department of Layton Rahmatulla Benevolent Trust Eye Hospital, Lahore. They were categorized in two groups based on the presence and absence of diabetic retinopathy. Period: $1^{\text {st }}$ July, 2016 to $30^{\text {th }}$ Aug., 2017. Materials and Methods: Collected data from the 80 enrolled patients included gender, age, duration of type two diabetes mellitus and status of diabetic retinopathy after assessment by ophthalmologists. The anthropometric measurements i.e. height, weight and BMI were taken by following the protocols mentioned in National Health and Nutrition Examination Survey (NHANES)-anthropometry procedure manual 2009 (CDC, 2012). Body mass index was calculated as weight in $\mathrm{kg}$ divided by the square of height in meters. Data was analyzed on SPSS version 22. For comparison of both groups, Independent "t" Test or Mann-Whitney U tests was applied accordingly. Correlation was accessed by spearman correlation test. Result: Out of 80 type two diabetic patients, females outnumbered the males 50(62.5). Overall 42(52.5\%) had diabetic retinopathy of varying grade and eye involvement. Both study groups had matched age $(p=0.45)$. However, a significant difference of duration of diabetes was observed between the groups $(p=0.042)$. There was no significant difference of BMI between the groups $(p=0.380)$. BMI was not correlated with severity of diabetic retinopathy. Conclusion: Although being overweight and obesity is thought to be risk factor for the development of type two diabetes even than it do not predispose the diabetic individual to develop diabetic retinopathy.

Key words: $\quad$ Basal Metabolic Index, Diabetic Retinopathy, Nephropathy, Obesity, Type Two Diabetes Mellitus.

Article Citation: ljaz K, Bahoo MLA, Saeed M, Karamt B, Niaz S. Basal metabolic index and retinopathy in type 2 diabetics. Professional Med J 2019; 26(7):1051-1056. DOI: 10.29309/TPMJ/2019.26.07.3501

\section{INTRODUCTION}

Type-two diabetes mellitus (T2DM) is among the commonly prevailed disorders in Pakistan. ${ }^{1}$ Most of the morbidity and mortality is attributed to the complications related to chronic hyperglycemia of T2DM. A darker aspect among these complication is threat to vision produced by diabetic retinopathy (DR). ${ }^{2}$ Retinopathy in diabetes is one of the prominent reason of loss of sight in working age group of 30-70 years. ${ }^{1}$ However if identified early in its course DR is both preventable and treatable. ${ }^{3}$ Poor glycemic control, longer duration of diabetes as well as tendency of high blood pressure and abnormal lipid profile, all leads to increase incidence of development of diabetic retinopathy in type two diabetics. However, it has been reported that even with the control of above factors only limited effects could have achieved. So further exploration of influential risk factors might be beneficial. ${ }^{4}$ Being overweight and obese are 2 risk factors for diabetes mellitus which are linked together through insulin resistance. ${ }^{5,6}$ Almost 46 to $68 \%$ of population living in urbanized areas of Pakistan are obese. ${ }^{7}$ For the estimation of body mass the most frequently and reliably used parameter is Body mass index (BMI) which 
is obtained by dividing the weight in kilograms by the square of the height in meters. ${ }^{8}$ In 2000 , WHO redefined the lower limit values for the verdict of being overweight and obese for the population of Asia and Pacific regions. According to that report $\mathrm{BMI}$ was ranked in to the following categories: underweight $\left(<18.5 \mathrm{~kg} / \mathrm{m}^{2}\right)$, normal weight (18.5 $\left.\mathrm{kg} / \mathrm{m}^{2}-23 \mathrm{~kg} / \mathrm{m}^{2}\right)$, overweight $\left(23 \mathrm{~kg} / \mathrm{m}^{2}-25 \mathrm{~kg} / \mathrm{m}^{2}\right)$ and obese $\left(\geq 25.0 \mathrm{~kg} / \mathrm{m}^{2}\right)^{9}$ The major morbidities of T2DM like nephropathy and cardiovascular involvement are thought to be linked with higher BMI. ${ }^{10}$ However the link between DR and BMI is still inconclusive. ${ }^{11}$ Some studies reported the higher incidence of DR with obesity. ${ }^{12,13}$

While some studies observed a decreased incidence of DR in higher BMI individuals ${ }^{14,15}$ and still few other studies noticed an insignificant association between obesity and the occurrence of DR. ${ }^{16}$

In order to find the trend in local population we explored the comparison and correlation in type two diabetics with and without diabetic retinopathy.

\section{METHOD}

This cross sectional study included, type two diabetic patients with or without DR who were selected from the outpatient department of Layton Rahmatulla Benevolent Trust Eye Hospital, Lahore. Written informed consent was taken. The demographic information of all the participants were collected. Each subject was assessed by performing physical examination, using specially designed Performa. DR status was accessed by an expert ophthalmologist (consultant) through indirect ophthalmoscopy with the help of Superfield 90D lens. The patients were categorized according to stages of DR. ${ }^{17}$

Anthropometric measurements i.e. height and weight were recorded of the patients with light clothing and bare foot using portable stadiometer and a weighing scale respectively by following the protocols mentioned in National Health and Nutrition Examination Survey (NHANES)anthropometry procedure manual $2009 .{ }^{18}$ Body mass index was calculated as weight in $\mathrm{kg}$ divided by the square of height in meters $(\mathrm{kg} /$ $\mathrm{m}^{2}$ ). Data were obtained and analyzed using IBM SPSS for Windows software (version 22). Mean \pm SD or median \pm interquartile range (depending upon normality or non-normality of data determined by Shapiro-Wilk test) were given for quantitative variables like age, height, weight and BMI. Frequencies and percentage were used for qualitative variables like gender, groups etc Depending on the data normality (Shapiro-Wilk), either Independent "t" Test or Mann-Whitney U tests for comparison of quantitative data were applied. $\mathrm{P}<0.05$ were considered statistically significant. For correlation of $\mathrm{BMI}$ and $\mathrm{DR}$ spearman rho correlation was used.

\section{RESULT}

\begin{tabular}{|c|c|c|}
\hline $\begin{array}{c}\text { Qualitative } \\
\text { variables }\end{array}$ & $\begin{array}{c}\text { T2DM with diabetic } \\
\text { retinopathy } \\
n=42\end{array}$ & $\begin{array}{c}\text { T2DM without } \\
\text { diabetic } \\
\text { retinopathy } \\
n=38\end{array}$ \\
\hline $\begin{array}{l}\text { Gender } \\
M / F\end{array}$ & $40.47 / 59.52$ & $34.20 / 65.80$ \\
\hline $\begin{array}{l}\text { Eye } \\
\text { involvement } \\
\text { Unilateral/ } \\
\text { Bilateral }\end{array}$ & $11.90 / 88.10$ & $0.00 / 0.00$ \\
\hline \multicolumn{3}{|c|}{$\begin{array}{c}\text { Table-I. Gender and eye involvement distribution of } \\
\text { type two diabetic patients }\end{array}$} \\
\hline
\end{tabular}

In current study, 80 patients with type two diabetes mellitus (T2DM) were included which were further divided on the basis of presence of diabetic retinopathy in to two groups. One is diabetic retinopathy group and other is non-diabetic retinopathy group. Diabetic retinopathy group included 42, type 2 diabetic individuals having diabetic retinopathy. Non-diabetic retinopathy group included 38 type two diabetic individuals but without diabetic retinopathy.

Out of 42 type two diabetic individuals with diabetic retinopathy, only 17 (40.48\%) were males having diabetic retinopathy while 25 (59.52\%) were females with diabetic retinopathy. In non-diabetic retinopathy group of 38 subjects, 13 (34.2\%) were male and $25(65.8 \%)$ were females without diabetic retinopathy. Out of total 80 specimens 30 (37.5\%) were males and 50 (62.5\%) were females. 
In diabetic retinopathy group $5(11.90 \%)$ patients had unilateral diabetic retinopathy while 37 (88.10 $\%)$ had bilateral diabetic retinopathy. In nondiabetic retinopathy group no eye involvement was seen for diabetic retinopathy.

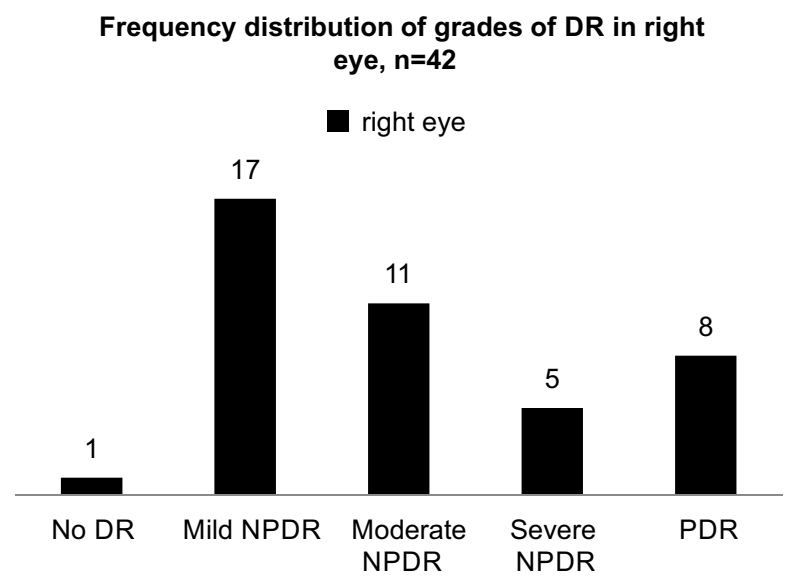

Figure-1. Frequency distribution of grades of diabetic retinopathy in right eye

Frequency distribution of grades of DR in left eye, $n=42$

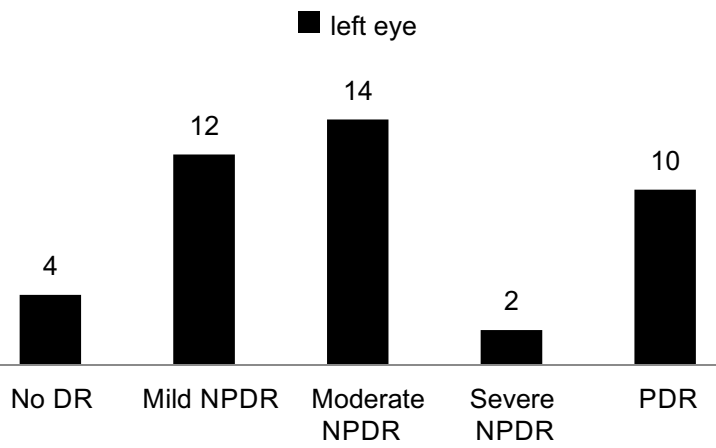

Figure-2. Frequency distribution of grades of diabetic retinopathy in left eye

\begin{tabular}{|c|c|}
\hline \multirow{3}{*}{ Parameters } & $\begin{array}{c}\text { Type } 2 \text { diabetics with } \\
\text { diabetic retinopathy } n=42\end{array}$ \\
\hline & Mean \pm SD \\
\hline & Median(IQR) \\
\hline \multirow[t]{2}{*}{ Age (Years) } & $53.00 \pm 6.28$ \\
\hline & $53.00(49.75-60.00)$ \\
\hline \multirow{2}{*}{ Duration of Diabetes (Years) } & $9.28 \pm 5.36$ \\
\hline & $8.50(5.00-12.00)$ \\
\hline \multirow{2}{*}{$\begin{array}{l}\text { Height } \\
\text { (M) }\end{array}$} & $1.61 \pm 0.08$ \\
\hline & $1.61(1.52-1.70)$ \\
\hline \multirow{2}{*}{$\begin{array}{l}\text { Weight } \\
\text { (Kg) }\end{array}$} & $68.62 \pm 11.26$ \\
\hline & $69.00(59.00-75.00)$ \\
\hline \multirow{2}{*}{$\begin{array}{l}\text { Body Mass Index } \\
\text { (BMI) }\end{array}$} & $26.53 \pm 4.44$ \\
\hline & $25.53(23.80-28.78)$ \\
\hline
\end{tabular}

Table-II. Comparison of study parameters between the study groups
Median (IQR) age in diabetic retinopathy group is $53.00(49.75-60.00)$ and in non-diabetic retinopathy group is $55.00(50.00-58.25)$ A non-significant difference was observed on comparison of ages of two groups by Maan whitney $U$ test $(p=0.45)$.

In diabetic retinopathy group, Median (IQR) diabetes duration was 8.50 (5.00-12.00) and in non-diabetic retinopathy group, Median (IQR) diabetes duration was 7.50 (5. 00-10.00). It was observed by Maan whitney $U$ test that there was significant difference between Median (IQR) of duration of diabetes of both the groups $(p=0.042)$.

The height in the diabetic retinopathy group was normally distributed among the individuals of group with the mean of $1.61 \pm 0.08 \mathrm{~m}$ while it had non-normal distribution among nondiabetic retinopathy group with the median IQR of 1.58(1.52-1.64) m. Maan whitney $U$ test revealed non-significant difference. $(p=0.63)$.

Weight was normally distributed among all the individuals of both diabetic retinopathy group and non-diabetic retinopathy group with the mean of $68.62 \pm 11.26 \mathrm{~kg}$ and $70.42 \pm 14.03 \mathrm{~kg}$ respectively with non-significant difference as observed by student $t$ test $(p=0.52)$.

Median IQR BMI in diabetic retinopathy group is 25.53 (23.80-28.78) and mean in non-diabetic retinopathy group is $27.50 \pm 5.38$. A non-significant difference was observed on comparison of BMl of two groups by Maan whitney $U$ test $(p=0.380)$.

Type 2 diabetics without

diabetic retinopathy $n=38$

$$
\text { Mean } \pm \text { SD }
$$

Median(IQR)

$53.92 \pm 4.58$

55.00(50.00-58.25)

$7.11 \pm 3.79$

7.50 (5.00-10.00)

$1.60 \pm 0.08$

1.58(1.52-1.64)

$70.42 \pm 14.03$

70.50 (58.75-84.25)

$27.50 \pm 5.38$

27.37 (22.94-30.95)

$0.453^{b}$

$0.042^{\star b}$

$0.639^{b}$

$0.526^{a}$

$0.380 b$
P-Value 


\begin{tabular}{|c|c|c|c|c|}
\hline & \multicolumn{2}{|c|}{ Correlation of Left Eye Involvement } & \multicolumn{2}{c}{ Correlation of Right Eye Involvement } \\
\cline { 2 - 4 } & $\begin{array}{c}\text { Spearman's rho } \\
\text { Correlation Coefficient }\end{array}$ & p-Value* & $\begin{array}{c}\text { Spearman's rho } \\
\text { Correlation Coefficient }\end{array}$ & P-Value* \\
\hline BMI & -0.074 & 0.517 & -0.045 & 0.777 \\
\hline
\end{tabular}

Table-III. Correlation of eye involvement with BMI in type 2 diabetics patients $n=42$

We could not find any significant correlation between varying grades of diabetic retinopathy in both eyes with BMI in type two diabetics with diabetic retinopathy.

\section{DISCUSSION}

Diabetes mellitus is among one of the very common ailments of the Pakistan and has always been an area of much interest for the researchers. The ever rising number of DM and its related morbidities due to its macrovascular (cardiovascular disease, cerebrovascular disease and peripheral artery disease) derangements results in demise of the $70 \%$ patients. Furthermore, microvascular complications that affect eyes (retinopathy), kidneys (nephropathy), and peripheral nerves (neuropathy) lowers the quality of the life imparting a great financial and social burden on suffering families and society, at larger, as well. ${ }^{19}$

Diabetic retinopathy (DR), the frequent origin of irreversible sightlessness in working-age population in developed world, effects the central vision and subsequently its demise occurring due to microvascular damage to the inner lining of the back of the eye, the retina. ${ }^{20}$ Diabetic retinopathy is commonly occurring problem of diabetic mellitus which causes the vision loss. ${ }^{21}$ Previously, in Pakistan the occurrence of DR was reported at $26 \%$ but it has now progressed to $59 \%$. ${ }^{22}$

Longer duration of disease predispose the diabetic patient to develop diabetic retinopathy. ${ }^{4}$ On comparison of duration of diabetes between both groups, it was observed that DR group had higher duration of DM than the non-DR group and this difference was $(p=0.042)$. These results are consistence with the results of few other studies..$^{23,24,25}$ Thus our study is also validating the the fact that incidence of retinopathy has strong association with duration of diabetes. ${ }^{26}$ This emphasizes the need for regular screening of diabetics for detection of retinopathy in the early stages.

Furthermore, the mainfocus and target oftreatment has always been to achieve the optimum levels of blood glucose along with blood pressure, in order to minimize the hazards of microvascular complications such as development and progression of diabetic retinopathy. However, though reduction in development and progression of diabetic retinopathy can be achieved by very good control of blood sugar levels along with blood pressure but still complete prevention of this sight threating condition is not possible. ${ }^{4}$ Therefore, the probable contribution of many other mechanisms in development and progression of the diabetes and its microvascular complication has been assumed.

An association between obesity and type two diabetes mellitus exist which emphasize the worth exploring relationship between obesity and complications of diabetes mellitus. ${ }^{27}$ Our study reported a non-significant difference in BMI between type two diabetics with diabetic retinopathy and type two diabetics without diabetic retinopathy $(p=0.380)$, similar to the results of other studies. ${ }^{24,28}$ Contrary to the studies reported in above paragraph a study reported a statistically significant difference between BMI of individuals with DR and without DR. they also showed that subjects with DR had lower BMI then T2DM patients without DR. ${ }^{25}$ This result points towards the fact that the relationship between $\mathrm{BMI}$ and DR is still inconclusive and need further exploration. Elevated BMl do not increase the risk of DR. ${ }^{29}$ Moreover, the neutral effects of high $\mathrm{BMI}$ and obesity on DR are due to high levels of $\mathrm{C}$-peptide in obese individuals ${ }^{30}$ which may counteract the adverse effect of BMI and higher levels of vascular endothelial growth factor in obese individuals ${ }^{31}$ and these counterbalancing effects minimizes the involvement of growth 
factors in the pathogenesis of proliferative DR. ${ }^{32}$

\section{CONCLUSION}

This study reported that diabetic patients with diabetic retinopathy have higher duration of disease as compared to diabetic patients without diabetic retinopathy. This emphasize on frequent evaluation of the patient to prevent the development and further progression of the disease. Moreover, our study found a nonsignificant difference of BMI between the study groups along with it non- significant correlation between severity of diabetic retinopathy and $\mathrm{BMI}$ was found. Although generally the BMI is considered as a guide to evaluate generalized obesity, it is not an accurate parameter to reflect adiposity of the body as it also includes muscles and bone mass, other anthropometric measurements such as circumference of the waist and waist to hip ratio should also be used to explore the link between obesity and DR. Studies in these directions with higher numbers of samples and all other related metabolites are obligatory to outline their role.

Copyright@ 25 June, 2019.

\section{REFERENCE}

1. Diabetes statistics in Pakistan. [Internet] 2013 Oct 5. [Cited July 6 2015]. Available from:<http:// diabetespakistan.com/treatment/ABC-of-Diabetes/ 2013/10/05/diabetes-statistics-in-pakistan>.

2. Stratton IM, Adler AI, Neil HA, Mathews DR, Manley SE, Cull CA, et al. Association of glycaemia with macro vascular and microvascular complications of type 2 diabetes (UKPDS 35): Prospective observational study. BMJ. 2000 Aug; 321 (7258):405-12.

3. Ellis D, Burgess PI, Kayange P. Teaching corner: Management of diabetic retinopathy. Malaawi medical journal. 2013 Dec; 25(4):116-20.

4. Kaštelan S, Tomić M, Gverović Antunica A, Ljubić S, Salopek Rabatić J, Karabatić M. Body mass index: a risk factor for retinopathy in type 2 diabetic patients. Mediators Inflamm. 2013; 2013:436329.

5. Zhou $Y$, Zhang $Y$, Shi $K$, Wang $C$. Body mass index and risk of diabetic retinopathy: $A$ meta-analysis and systematic review. Medicine. 2017; 96:22.

6. Al-Goblan AS, Al-Alfi MA, Khan MZ. Mechanism linking diabetes mellitus and obesity. Diabetes, Metabolic Syndrome and Obesity: Targets and Therapy. 2014; 7:587-591.
7. Basit A, Shera AS. Prevalence of metabolic syndrome in Pakistan. Metab Syndr Relat Disord. 2008 Sep; 6(3):171-5.

8. Criqui MH, Klauber MR, Barrett-Connor E, Holdbrook MJ, Suarez L, Wingard DL. Adjustment for obesity in studies of cardiovascular disease. Am J Epidemiol 1982; 116:685-91.

9. The Asia-Pacific perspective: Redefining obesity and its treatment. Melbourne: Health communications Australia; 2000. WHO/IASO/IOTF.

10. Maric C, Hall JE. Obesity, metabolic syndrome and diabetic nephropathy. Contrib Nephrol. 2011 Jun; 170:28-35.

11. Lu J, Hou X, Zhang L, Jiang F, Hu C, Bao Y, Jia W. Association between body mass index and diabetic retinopathy in Chinese patients with type 2 diabetes Acta Diabetol. 2015 Aug; 52(4):701-8.

12. Van Leiden HA, Dekker JM, Moll AC, Nijpels G, Heine RJ, Bouter LM et al. Blood pressure, lipids, and obesity are associated with retinopathy: The hoorn study. Diabetes Care 2002 Aug; 25(8):1320-5.

13. Tolonen N, Hietala K, Forsblom C, Harjutsalo V, Mäkinen VP, Kytö $\mathrm{J}$ et al. Associations and interactions between lipid profiles, retinopathy and nephropathy in patients with type 1 diabetes: The FinnDiane Study. J Intern Med. 2013 Nov; 274(5):469-79.

14. Lim LS, Tai ES, Mitchell P, Wang JJ, Tay WT, Lamoureux $E$ et al. C-reactive protein, body mass index, and diabetic retinopathy. Invest Ophthalmol Vis Sci. 2010 Sep; 51 (9):4458-63.

15. Rooney $\mathrm{D}^{1}$, Lye WK, Tan G, Lamoureux EL, Ikram $\mathrm{MK}$, Cheng $\mathrm{CY}$ et al. Body mass index andretinopathy in Asian populations with diabetes mellitus. Acta Diabetol. 2015 Feb; 52(1):73-80.

16. Lima VC, Cavalieri GC, Lima MC, Nazario NO, Lima GC. Risk factors for diabetic retinopathy: A case-control study. Int J Retina Vitreous. 2016; 2:21.

17. Wilkinson $C P$, Ferris FL, Klein RE, Lee PP, Agardh $C D$, Davis $M$ et al. Proposed international diabetic retinopathy and diabetic macular edema disease severity scale. Ophthalmology, 2013; 110(9): 1677-82.

18. Center for disease control and prevention [Internet] 2012. [Accessed 09 March, 2018] National Health and Nutrition Examination and Survey (NHANES)Anthropometry procedures manual 2009. [Online] available from: <http://www.cdc.gov/nchs/nhanes/ nhanes2009-2010/current_nhanes_09_10.htm >. 
19. Stitt AW, Curtis TM, Chen M, Medina RJ, McKay GJ, Jenkins $A$ et al. The progress in understanding and treatment of diabetic retinopathy. Prog. Retin. Eye Res., 2016; 51:156-86.

20. Lu Q, Lu P, Chen W, Lu L, Zheng Z. ANGPTL-4 induces diabetic retinal inflammation by activating Profilin-1. Exp. eye res. 2018 Jan; 166: 140-50.

21. Nentwich MM, Ulbig MW. Diabetic retinopathy - ocular complications of diabetes mellitus. World J Diabetes. 2015; 6(3):489-99.

22. Sohail M. Prevalence of diabetic retinopathy among type -2 diabetes patients in Pakistan. Pak. J. Ophthalmol., 2014; 30: 204-12.

23. Morita S, Kasayama S, Deguchi R, Hirai K, Mukai K, Utsu $Y$ et al. Glycated albumin, rather than HbA1c, reflects diabetic retinopathy in patients with type 2 diabetes mellitus. J Diabetes metab. 2013; 4(6):27881.

24. Pan J, Li Q, Zhang L, Jia L, Tang J, Bao Y, Jia W. 2014. Serum glycated albumin predicts the progression of diabetic retinopathy -a five years retrospective longitudinal study. J Diab Complic. 2014 Jul; 28(6):7728.

25. Jeon W.S, Park SE, Rhee EJ, Lee WY, Oh KW, Park SW et al. The association of serum glycated albumin with the prevalence of diabetic retinopathy in Korean patients with type two diabetes mellitus. Diabetes Res Clin Pract. 2016 Jun; 116:46-53.
26. Niazi MK, Akram A, Naz MA, Awan S. Duration of diabetes as a significant factor for retinopathy. Pak $\mathrm{J}$ Ophthalmol. 2010; 26(4): 182-6.

27. Gray N, Picone G, Sloan F, Yashkin A. Relation between BMI and diabetes mellitus and its complications among US older adults. South Med J. 2015; 108(1):2936.

28. Umayahara Y, Fujita Y, Watanabe H, Kasai N, Fujiki N, Hatazaki $\mathrm{M}$ et al. Association of glycated albumin to HbA1c ratio with diabetic retinopathy but not diabetic nephropathy in patients with type 2 diabetes. Clin. Biochem. 2017; 50(6): 270-3.

29. Zhou Y, Zhang Y, Shi K, Wang C. Body mass index and risk of diabetic retinopathy. A meta-analysis and systematic review. Medicine (Baltimore). 2014; 96: 22.

30. Cai X, Han X, Zhang S, Luo Y, Chen Y, Ji L. Age at diagnosis and $C$-Peptide level are associated with diabetic retinopathy in Chinese. PLoS one. 2014 Mar; 9(3): e91174.

31. Miyazawa-Hoshimoto S, Takahashi K, Bujo H, Hashimoto $\mathrm{N}$, Saito Y. Elevated serum vascular endothelial growth factor is associated with visceral fat accumulation in human obese subjects. Diabetologia. 2003; 46(11): 1483-8.

32. Tarr MJ, Kaul K, Chopra M, Kohner EM, Chibber R. Pathophysiology of diabetic retinopathy. ISRN ophthalmology. 2013:1-13.

\begin{tabular}{|c|l|l|l|}
\hline \multicolumn{3}{|c|}{ AUTHORSHIP AND CONTRIBUTION DECLARATION } \\
\hline Sr. \# & Author-s Full Name & \multicolumn{1}{|c|}{ Contribution to the paper } & Author=s Signature \\
\hline 1 & Kanwal ljaz & $\begin{array}{l}\text { Article design, review of literature, } \\
\text { data collection \& analysis. }\end{array}$ \\
\hline 2 & M. Luqman Ali Bahoo & Final critical review of article. \\
\hline 3 & Mahwish Saeed & Data collection. \\
\hline 4 & Beenish Karamt & Review of literature. \\
\hline 5 & Sobia Niaz & Data analysis. & \\
\hline
\end{tabular}

